\title{
SUBJETIVIDADES
}

Estudo Teórico

e-ISSN: 2359-0777

\section{MEDICALIZAÇÃO DA VIDA E SUAS IMPLICAÇÕES PARA A CLÍNICA PSICOLÓGICA CONTEMPORÂNEA}

\author{
Medicalization of Life and its Implications for the Contemporary Clinical Psychology
}

Medicalización de la Vida y sus Implicaciones para la Clínica Psicológica Contemporánea

\section{La Médicalisation de la Vie et sa Relation avec la Psychologie Clinique Contemporaine}

DOI: $10.5020 / 23590777 . r s . v 17 i 3.5813$

\author{
Lívia Machado Silva (Lattes) \\ Aluna do Programa de Mestrado em Psicologia da Universidade Federal Rural do Rio de Janeiro. (PPGPSI). \\ Fernanda Canavêz (Lattes) \\ Doutora em Teoria Psicanalítica (UFRJ), Profa do Departamento de Psicologia e do Programa de Pós Graduação em Psicologia da UFRRJ.
}

\begin{abstract}
Resumo
Este artigo busca analisar as demandas contemporâneas endereçadas à clínica e sua relação com a cultura de medicalização da vida. Para alcançar esse objetivo, optou-se pela realização de um levantamento bibliográfico relativo ao termo medicalização. Adotou-se a visão trazida por Ivan Illich e Peter Conrad por entender que ambos os autores fomentaram, ao longo de sua obra, um importante desenvolvimento da abordagem crítica referente ao tema. Por fim, busca-se analisar algumas demandas atuais no campo da clínica psicológica à luz de uma crítica sobre o processo de medicalização.
\end{abstract}

Palavras-chave: medicalização; clínica psicológica; contemporâneo.

Abstract

This article seeks to analyze the contemporary demands addressed to clinical psychology and how they are related with the culture of medicalization. For this, we have decided to do a literature review concerning the term 'medicalization'. We have adopted the vision brought by Ivan Illich and Peter Conrad understanding that both authors have fostered throughout their work an important development and a critical approach on this subject. Finally, this article seeks to analyze some of the present demands in the field of clinical psychology under the light of a critic of the process of medicalization.

Keywords: medicalization; clinical psychology; contemporary.

\section{Resumen}

Este artículo pretende analizar las demandas contemporáneas dirigidas a la psicología clínica y su relación con la cultura de la medicalización. Para ello, hemos decidido hacer una revisión de la literatura sobre el término 'medicalización'. Hemos adoptado la visión aportada por IvanIllich y Peter Conrad de que ambos autores han fomentado a lo largo de su trabajo un importante desarrollo y un enfoque crítico sobre este tema. Finalmente, este artículo pretende analizar algunas de las demandas actuales en el campo de la psicología clínica a la luz de una crítica del proceso de medicalización.

Palabras clave: medicalización; psicología clínica; contemporáneo. 


\section{Résumé}

Cet article cherche à analyser les demandes contemporaines adressées à la psychologie clinique et à la relation avec la culture de la médicalisation. Pour cela, nous avons décidé de faire un examen de la littérature concernant le terme 'médicalisation'. Nous avons adopté la vision apportée par Ivan Illich et Peter Conrad, selon laquelle les deux auteurs ont favorisé tout au long de leur travail un développement important et une approche critique à ce sujet. Enfin, cet article cherche à analyser certaines des exigences actuelles dans le domaine de la psychologie clinique à la lumière d'un critique du processus de médicalisation.

Mots-clés: medicalisation; psychologie clinique; contemporain.

Muito se tem discutido a respeito do aumento das doenças nos últimos anos. Essa realidade é percebida em diferentes espaços, como a escola, as salas de espera dos consultórios médicos e também os atendimentos psicológicos. Os profissionais têm encontrado uma demanda crescente por diagnósticos que visam traduzir um cenário de busca intensa por um estado de saúde estampado nas capas de revista.

Desde a década de 1950, pesquisadores na área da sociologia têm buscado discutir a respeito das influências de determinados saberes como a ciência e a medicina no cotidiano dos indivíduos. $\mathrm{O}$ avanço desses estudos demonstra que a influência pode ser observada nos mais singelos comportamentos. O uso de vitaminas, a prática de atividades físicas, bem como o aumento no número de pessoas diagnosticadas com alguma enfermidade a partir de revistas ou reportagens de televisão, corroboram com um estado de patologização da vida, fenômeno que foi definido por medicalização.

A partir do uso desse termo pelo sociólogo Ivan Illich (1975), as pesquisas sociológicas buscaram circunscrever o processo a que ele estaria relacionado, e disso resultou um uso indiscriminado do termo, acarretando, muitas vezes, numa confusão conceitual. De acordo com Zorzanelli, Ortega e Bezerra Jr. (2014), essa confusão refere-se ao fato do processo ser tomado ora como crítica à expansão do poder médico, ora como uma crítica à visão que põe o poder médico no centro do fenômeno. Afirmam, então, os autores que, para o uso do termo medicalização, faz-se necessário discriminar a partir de qual ponto de vista se está partindo e a qual contexto a discussão se refere.

No campo da Psicologia, tem se observado um interesse crescente no tema da medicalização da vida (Guarido, 2007; Henriques, 2012; Uhr, 2012 e Viégas, Harayama \& Souza, 2015), fazendo com que constitua um território amplo de possibilidades investigativas. Compreendendo, portanto, as diversas conceituações existentes nesse processo, propõe-se uma revisão de literatura embasada em dois dos principais autores. O objetivo desta revisão é relativizar o uso do termo, especialmente na área da clínica psicológica, campo fértil para refletir sobre determinados discursos tidos como hegemônicos a respeito da saúde ou da doença.

Buscar-se-á relacionar a discussão sobre o fenômeno da medicalização da vida a partir dos estudos de Illich (1975), Conrad (1979; 1992; 2007) e Conrad e Barker (2011), com as demandas contemporâneas endereçadas à clínica psicológica. A escolha por esses autores se justifica pelo fato do primeiro ter sido um crítico radical do processo de medicalização na década de 1970, lançando, por exemplo, a ideia da iatrogênese sobre o campo de atuação médico. Entretanto, Illich revisitou suas críticas anos mais tarde demonstrando com isso uma aproximação com o pensamento de Conrad (1992; 2007), que afirma que a medicalização é um processo sócio-cultural que ultrapassa as fronteiras da medicina. Sendo assim, Conrad também foi eleito como um importante teórico para a discussão doravante empreendida. Encontram-se entre as demandas citadas anteriormente a expansão de diagnósticos e síndromes nas últimas décadas, bem como o apelo aos especialistas, entre eles o profissional de Psicologia, que não raramente é convocado a responder em consonância com a lógica medicalizante.

Para efeito de exemplificação, serão adotados dois momentos históricos que permitem analisar a expansão do número de diagnósticos com base no CID-10 (Classificação Internacional de Doenças) e no DSM- IV (Manual Diagnóstico e Estatístico dos Transtornos Mentais). Acredita-se que o estudo sobre o tema coloca em pauta a possibilidade do debate acerca de práticas não medicalizantes relacionadas ao campo da clínica. Essa discussão é importante, pois revela, acima de tudo, dinâmicas e modos de pensar que insurgem contra o discurso e as práticas de poder ditas hegemônicas. Essa pretensa hegemonia fomenta o processo de medicalização da vida, produzindo uma patologização do viver.

\section{A Revisão dos Manuais Diagnósticos e o Processo de Medicalização}

O ponto de partida para a discussão proposta nesse artigo, isto é, o estudo crítico a respeito da medicalização, será a análise de dois momentos, indicados no quadro anexado ao final do texto. Esse quadro se refere às revisões do Código 
Internacional de Doenças (CID), elaborado por Laurenti (1991), estando nele listadas, desde sua primeira edição, o número de doenças catalogadas, o ano de uso e o número total de categorias. É possível observar que na sexta edição, em 1948, houve um crescimento alarmante no número de doenças catalogadas (de 164 passa a registrar 769, um aumento de 368,9\%). O mesmo ocorre em 1989, quando há a atualização do código para a décima edição, utilizada até o presente momento (de 909 passa a registrar 1575, um aumento de 73,27\%). É possível traçar um comparativo dentro de um curto espaço de tempo, desde 1948 até 1989 (40 anos), no qual há um aumento de 101\% no número total de possíveis categorias diagnosticáveis.

Um movimento similar também foi observado no DSM (Manual Diagnóstico e Estatístico dos Transtornos Mentais). De acordo com Henriques (2015, p. 61), "o DSM-II, de 1968, listava 180 códigos classificatórios; com o DSM-III, de 1980, passou-se a 265, contingente aumentado para 374 com o advento do DSM-IV, em 1994, e para 450 no DSM-5, em 2013”.

Segundo o trabalho de Laurenti (1991) a respeito do desenvolvimento do Código Internacional de Doenças (CID), os fatores que culminavam em doenças que circunscreviam o campo da saúde mental e do trabalho começaram a fazer parte do referido manual a partir da sexta revisão. Essa inclusão ocorreu em 1948, período em que as doenças mentais e do comportamento ganham um espaço diferenciado dos demais diagnósticos. Aliás, foi a partir da sexta revisão do CID que houve uma mudança de classificação de doenças, elas passaram a diagnosticar não apenas as causas de morte, mas também as morbidades, os fatores que contribuem para o aparecimento ou agravamento de determinada doença (Laurenti, 1991).

Os dois períodos destacados -os anos de 1948 e 1989 - refletem condições sociais, políticas e econômicas diferentes. O primeiro tem proximidade com o final da Segunda Guerra Mundial (1945), momento que se configurou pela reestruturação dos países europeus, pela imigração de um contingente populacional, entre eles cientistas e intelectuais, para os Estados Unidos e também pela emergência de uma nova ordem político-econômica mundial. Essas condições influenciaram a produção científica e, em especial, o saber médico e o desenvolvimento da profissão médica em diversos países. Uma das causas do aumento do número de categorias diagnósticas citadas por Laurenti (1991) foi a mudança de perspectiva relacionada ao CID, uma vez que a OMS (Organização Mundial de Saúde), a partir de 1948, assume as revisões do Código.

O segundo período destacado foi o ano de 1989, ano da queda do Muro de Berlim e a expansão e refinamento da ideologia neoliberal. Nos limites do presente artigo, a contemporaneidade será compreendida como um período marcado por sensíveis transformações (dentre elas o fenômeno da globalização), com o desenvolvimento dos meios de comunicação e o surgimento da internet (Jardim \& Oliveira, 2009). O neoliberalismo pode ser definido como um conjunto de ideias políticoeconômicas que enfatizam a não participação do Estado na economia, a flexibilização dos contratos de trabalho, a abertura nacional para empresas de outros países, entre outras características. Nos EUA, por exemplo, há um forte desenvolvimento das indústrias automobilísticas, farmacêuticas e alimentícias que inauguram um novo modo de relacionamento na sociedade. Nesse sentido, é possível afirmar que há uma produção de um modo de viver diferente, a saber: aquele que inaugura o consumo como um estilo de vida a ser alcançado.

De acordo com Birman (2006), é possível depreender que não há consenso entre os autores a respeito do início da contemporaneidade nem mesmo se seria pertinente falar em termos da inauguração de um novo período que teria sucedido a modernidade. Para os limites desse artigo, no entanto, adotar-se-á o recorte historiográfico considerado mais tradicional como referência. Desse modo, caracterizar-se-á o período chamado de modernidade como aquele compreendido entre os séculos XVII e XIX. Nesse período de grandes transformações para a humanidade, a Revolução Francesa e a Revolução Industrial têm um papel de destaque, pois trouxeram consigo a ideologia Iluminista, os princípios do capitalismo, a formação dos Estados-Nação, o pensamento científico pautado na razão e, sobretudo, uma nova organização social que enfraquecia as marcas da monarquia absolutista (Rocha, 2012). Já o período que será chamado aqui de contemporaneidade, a despeito da ampla discussão que o termo sugere entre os historiadores, pode ser apontado, de acordo com Hobsbawm (1995), como tendo seu início no fim do século XIX e especialmente na eclosão da Primeira Guerra Mundial.

Feita essa pequena digressão explicativa, são observadas duas datas que podem ser inseridas no período caracterizado como contemporaneidade, a saber, 1945 e 1989. A escolha desses dois momentos justifica-se, em primeiro lugar, pela possibilidade de compreender a influência de alguns fatores, como a situação política e econômica, nas questões ligadas à saúde. E, em segundo lugar, esses períodos servem para análise uma vez que foi a partir deles que a produção técnica e científica relacionada à saúde obteve um desenvolvimento significativo. Esse fato é também uma ponte para a discussão que se segue, isto é, para a análise do fenômeno da medicalização.

\section{Método}

Trata-se de ensaio teórico decorrente de uma revisão sistemática da literatura acerca do tema da medicalização e suas implicações para o campo da clínica psicológica. Para tal, foram pesquisados artigos, teses e dissertações na base de periódicos da Capes e em seus bancos de teses e dissertações. A biblioteca SciELO também foi consultada e os termos 
utilizados para busca foram: medicalização e clínica. A partir do material pesquisado, focalizou-se as teorias de Ivan Illich, sobretudo o segundo momento de sua obra, bem como a de Peter Conrad, as quais vão ressaltar o aspecto social presente na cultura da medicalização. Esses autores foram privilegiados no recorte, buscando-se articular seus principais conceitos para, em seguida, extrair as implicações dessa reflexão no campo da clínica na contemporaneidade.

\section{Reflexões acerca do Conceito de Medicalização: Contribuição Ivan Illich e Peter Conrad}

A partir da década de 1950 houve um crescente interesse por parte de pesquisadores da área médica e das ciências humanas em relação aos temas ligados à saúde. Nesse período, começaram a surgir vários estudos sobre os efeitos do saber médico na sociedade, como já foi apontado anteriormente.

Buscou-se no artigo de Zorzanelli et al. (2014) a discussão referente ao uso do termo medicalização tendo em vista seu caráter generalista que configura, de acordo com os autores, grande parte das publicações relacionadas ao tema. A contribuição do trabalho supracitado se faz notar pela explicitação dos diferentes sentidos atribuídos ao conceito de medicalização. Os autores tratam a temática utilizando pensadores como Foucault, Illich, Zola, Conrad, entre outros, mostrando como cada um deles entende o fenômeno, contextualizando-o à sua época. Optar-se-á pela escolha de dois autores neste artigo, a saber, Illich e Conrad.

É importante lembrar ao leitor da existência de outros autores como Irving Zola, Thomas Szasz e o próprio historiador Michel Foucault, que são frequentemente retomados como autores de extrema relevância no estudo sobre medicalização. Entretanto, para os limites deste artigo, serão ressaltados alguns posicionamentos feitos por Illich (1975) eas reflexões feitas por Conrad $(1992 ; 2007)$ a fim de demonstrar distanciamentos e aproximações na forma como cada autor trata o tema. Esses autores, apesar de serem contemporâneos a outros da década de 1970, revelam tanto sobre o fenômeno quanto sobre o seu próprio posicionamento, enaltecendo outros aspectos, como os conflitos de ordem social, política e econômica, além dos processos históricos frente ao desenvolvimento da medicina e da indústria farmacêutica, e também o papel da mídia na cultura contemporânea. Todos esses fatores ultrapassam a noção predominante que assumia o imperialismo do saber médico como única causa da medicalização.

O sociólogo Ivan Illich foi um dos primeiros e mais radicais críticos do processo de expansão do saber e poder da medicina sobre a sociedade. Em seu ilustre livro Nêmesis: a expropriação da saúde (1975), o autor abre a discussão afirmando que a empresa médica é uma ameaça à saúde, aliena a sociedade e impede, através do seu monopólio médico, que o conhecimento seja compartilhado. Em momento posterior, Illich reavalia seu posicionamento a respeito desse fenômeno e acrescenta o papel da sociedade. De acordo com Nogueira (2003), Illich passa a falar sobre uma necessidade obsessiva que seria produzida em torno da saúde e observada nas décadas posteriores, 1980 e 1990 . Não se trata, portanto, de um monopólio ou imperialismo da medicina, mas de uma produção de urgência relativa ao auto-cuidado, na qual o cliente, ou cidadão comum, é transformado em uma nova espécie de profissional da saúde.

Já o sociólogo Conrad (1992; 2007), desde os seus trabalhos na década de 1970, alertava para o papel ativo dos indivíduos. Segundo Zorzanelli et al. (2014), o sociólogo busca evidenciar a medicalização como um processo irregular, diferente do que os seus contemporâneos postulavam. Para ele, é um fenômeno variável, desigual, dependente de seu alvo, do grupo social e dos mecanismos que concorrem para sua constituição. A escolha pela perspectiva desses autores a despeito de outros nomes de relevância para o tema se deve à possibilidade de ultrapassarem a barreira da crítica pautada exclusivamente na ação e controle da medicina sobre a sociedade e de ainda acrescentarem ao estudo o papel de outras dimensões, como a social e cultural.

Sabendo que o estudo da medicalização pode abarcar diversas vertentes de análise, foi realizado um quadro esquemático a partir do artigo de Zorzanelli et al. (2014), que busca trazer uma noção básica dos principais autores que abordam o tema (anexo 2).

Segundo Camargo Jr. (2013), a existência de diferentes conceitos sobre medicalização é reflexo do modo como é percebida a relação entre saúde e sociedade, pois as intervenções em relação à saúde podem assumir diferentes papéis dependendo do seu momento sócio-histórico.

Já nos primeiros capítulos, Illich (1975) aponta o histórico do desenvolvimento de algumas doenças, como a tuberculose e a difteria, e como desapareceram antes mesmo de uma possível intervenção do saber médico. Para ele, o fator que possibilitou a redução da mortalidade, especialmente na era moderna, não foi a atuação da medicina, e sim uma melhoria nos hábitos nutricionais da população.

Assim, Illich (1975) aponta em sua crítica que não era o fato do saber médico começar a catalogar as possíveis enfermidades e criar diagnósticos que reduzia os casos de doenças, mas o meio, incluindo o modo de vida da população, que tinha um papel primordial na identificação e redução de certas enfermidades. 
O autor propõe a ideia de uma patologia advinda da atuação da medicina sobre a vida, a qual chamará de iatrogênese (iatros $=$ médico; genesis $=$ origem). A iatrogênese clínica se refere às doenças que são causadas pelos cuidados com a saúde de modo geral, desde efeitos negativos decorrentes do uso de remédios de forma descontrolada até a postura negligente dos profissionais de saúde. Nas palavras do autor, "se referem às intervenções técnicas das profissões de saúde que são contraindicadas, erradas, brutais, inúteis, ou mesmo as prescritas de acordo com as regras" (Illich, 1975, p.31).

A iatrogênese social corresponde à produção de dependência dos postulados médicos pela sociedade, o que repercute no posicionamento de passividade e perda de autonomia frente à situação de saúde ou doença. $\mathrm{O}$ autor cita também os efeitos desse processo na sociedade, que parece impor um saber ao indivíduo deixando-o sem autonomia. Segundo ele,

A saúde do individuo sofre pelo fato de a medicalização produzir uma sociedade mórbida. A iatrogenia social é o efeito social não desejado e danoso do impacto social da medicina, mais do que o da sua ação técnica direta. Na essência a iatrogênese social é uma penosa desarmonia entre o indivíduo situado dentro de seu grupo e o meio social e físico que tende a se organizar sem ele e contra ele. Isso resulta em perda de autonomia na ação e no controle do meio (Illich, 1975, p.31).

Outra relação apresentada por Illich (1975) é a associação entre a medicina e a indústria farmacêutica. A incorporação da lógica farmacêutica no cotidiano dos indivíduos através da aproximação com os profissionais da medicina bloquearia a possibilidade de resistência daqueles. De acordo com Illich (1975), esse fato encontra respaldo no ato de mascarar as pesquisas que apresentam resultados contraditórios e que são financiadas pela indústria farmacêutica, o que retiraria a possibilidade dos indivíduos avaliarem a necessidade e a eficácia de um determinado medicamento.

Além disso, o autor discute como as diferentes formas de iatrogenia, principalmente a social, apresentam-se revestidas sob o rótulo da "modernização". Relata o caso da amamentação no Chile, em 1960, que era uma prática adotada por 96\% das mulheres no país e que passou para a faixa de 6\% em 1970. Essa mudança de hábito, segundo Illich (1975), deve-se à introdução de tecnologias como a mamadeira, e o status atribuído a elas, além de um novo olhar dirigido à saúde da mulher e ao processo de amamentação. Como resultado dessa nova prática, identificaram-se novas doenças nas crianças que não foram amamentadas pelo método tradicional.

Outro aspecto observado na crítica do autor é o comportamento, que passou a ser difundido a partir da década de 1970 , tanto pelo meio científico quanto pelo senso comum, de um cuidado prévio sobre a saúde. A medicalização da prevenção que atuaria nas possíveis circunstâncias ou causas do adoecimento, termo conhecido na literatura médica como a morbidade. Assim, ampliam-se as chances de atuação dos saberes médico e, por consequência, o número de possíveis diagnósticos.

Considerando os limites deste artigo, pode-se afirmar que a medicalização é definida por Illich como um processo no qual a supremacia do poder/saber médico sobre a vida dos indivíduos se articula com diferentes vias de atuação, a saber: a via clínica, a social e a cultural. Essas vias, por sua vez, têm como objetivo autorizar e rotular determinadas experiências com o corpo e sobre o corpo. Contudo essa perspectiva é revista pelo autor alguns anos após a publicação de seu livro Nêmesis, em 1975, fazendo com que seu estudo seja permeado por rupturas que alertam para o cuidado ao tomar um conceito sem explicitar a qual momento ele se refere.

Ele afirmará posteriormente que houve uma mudança na forma como a saúde passou a ser vista, de modo que resultou num declínio do poder médico. Esse aspecto pode ser ilustrado a partir das palavras de Zorzanelli et al. (2014, p. 1862): "nos anos 60, a profissão médica era proeminente em determinar o que o corpo é e como ele deveria sentir. Nos anos 70, ela começou a partilhar com outros agentes o poder de objetificar as pessoas".

Assim, inicia-se um processo de inauguração de novos saberes e estratégias para gerir a saúde e as novas doenças da sociedade. Tem-se aqui a importante contribuição da farmacologia, que será um campo de estudo propulsor do avanço da indústria farmacêutica e de sua relação direta com o consumidor. Um dos reflexos dessa mudança de postura é o autocuidado, que, de acordo com Nogueira (2003), tornou-se um produto a ser vendido e uma exigência normativa entre os indivíduos, uma vez que passa a não necessitar da mediação da figura do médico, o próprio consumidor é responsável por manter a sua saúde em dia.

Outro autor de relevância, cujos estudos sobre a medicalização são contemporâneos dos trabalhos de Illich, é o sociólogo Peter Conrad. De acordo com o trabalho de Conrad (1992; 2007), é possível afirmar que a definição de medicalização não é unânime. No entanto, a despeito de não possuir uma definição consensual, muitos estudiosos concordam com o fato de ser um processo em que instâncias cotidianas da vida se tornam objetos da jurisdição médica.

Ele afirma, num primeiro momento, que o controle social médico é uma aceitação da perspectiva médica como uma definição dominante sobre certo fenômeno, alinhando-se, de certa forma, ao posicionamento inicial de Illich (1975), visto anteriormente. Esse controle inclui conselhos, advertências e informações médicas que fazem parte do conhecimento comum, como a alimentação saudável e exercícios regulares. Para o autor, a medicalização do "desvio" é uma variante da intervenção médica que busca eliminar, modificar, isolar ou regular um comportamento socialmente definido como desviante a partir de significados médicos e em nome da saúde. Assim, define-se um comportamento como doença ou um 
sintoma de uma doença. Conrad (1979) destaca ainda os três tipos de controle social exercidos pela medicina, quais sejam: o da tecnologia médica, o da colaboração médica e o da ideologia médica. Os três tipos não são excludentes entre si. Aliás, é comum que eles estejam atuando juntos.

A tecnologia médica é o tipo mais comum de controle social de acordo com Conrad (1979), pois envolve a produção e comercialização de medicamentos para as mais diversas queixas. Desde remédios indicados para controle da doença mental até "desvios" comportamentais na infância. Essa forma de controleteria se popularizado devido à fácil administração dos medicamentos e ao fato deles serem autorizados pelos profissionais da área médica. A colaboração médica se refere às parcerias entre o saber médico e outras autoridades/saberes, como a Justiça.

Já a ideologia médica envolve a definição de um comportamento enquanto doença, principalmente por causa dos benefícios sociais e ideológicos que se pode obter. Dessa forma, a ideologia utiliza a autoridade médica através da linguagem, ou seja, adota o vocabulário ou imaginário médico para tratar um determinado problema. Conrad (1979) cita como exemplo o caso do grupo AA (Alcoólicos Anônimos), organização não médica, de autoajuda, que se utiliza de um determinado modelo conceitual em relação ao alcoolismo independente da profissão médica.

Como exemplifica Conrad (1979; 1992), os estudos sobre hiperatividade em crianças, a doença mental, o alcoolismo, entre outros, foram adquirindo espaço e visibilidade para discussão no campo da sociologia médica. Estudos da década de 1970 tinham como foco a análise de situações não médicas que ganham não só a definição, mas também o tratamento médico.

No texto intitulado Medicalizationand social control, Conrad (1992) cita que a chave para entender a medicalização se constitui no esclarecimento da definição utilizada. Desse modo, ele observa que é um processo no qual se define um comportamento como problema ou doença e se autoriza a profissão médica a realizar algum tipo de intervenção e de tratamento. Nesse sentido, o autor defende que este processo pode ser conceituado a partir da tomada de problemas não médicos que se tornam da alçada médica, geralmente em termos de doenças ou transtornos, usando uma linguagem ou intervenção médica para tratar o problema.

Ele afirma que esse é um processo irregular e sociocultural que pode, ou não, envolver a profissão médica, da mesma forma que pode, ou não, conduzir a um controle social ou a um tratamento médico, e ainda pode, ou não, ser resultado de uma expansão intencional da profissão médica. Este fato permite ao autor identificar uma dinâmica sociocultural na construção do fenômeno da medicalização, uma vez que o comportamento só é visto como doença posteriormente a uma intervenção social. A esse ponto de vista é possível acrescentar o papel determinante dos indivíduos na construção do fenômeno, aspecto que se aproxima com o que foi trazido por Nogueira (2003) quando aborda a segunda crítica feita por Illich.

Com base nesses estudos, Conrad (1992; 2007) vai afirmar que o processo de medicalização é uma via dupla, que inclui também a possibilidade de uma reversão em termos de uma espécie de desmedicalização. De acordo com esse entendimento, a desmedicalização seria a mudança de status de algo que já foi, em algum momento, definido em termos médicos. A título de esclarecimento, um exemplo de desmedicalização na literatura foi a retirada do termo "homossexualidade", em 1973, na versão do DSM III, publicada em 1980. Foi preciso uma organização dos grupos homossexuais e simpatizantes, bem como um apoio de parte da sociedade, para que a homossexualidade deixasse de ser vista e tratada como doença. É importante observar que um movimento como esse mobiliza primordialmente os paradigmas sociais vigentes. Segundo o autor "a desmedicalização só é alcançada usualmente depois de algum movimento organizado que desafie o controle e definições médicas" (Conrad, 1992, p.224).

A respeito do tema da desmedicalização da homossexualidade, ainda é possível colocar em pauta o fato de, apesar de não constar nos manuais diagnósticos, as práticas medicalizantes ainda se fazerem presentes. Um exemplo disso é o discurso da "cura gay", atualmente difundido por religiosos e profissionais de saúde. Para exemplificar essa questão, recentemente, em uma rede social, um homem divulgou um curso on-line com o objetivo de "prevenir, tratar e curar" as pessoas acometidas pelo "homossexualismo". Segundo a reportagem:

Claudemiro afirma que as aulas terão orientações para famílias e educadores à luz da Ciência e da Bíblia. Para dar mais credibilidade ao curso, ele enumera também suas possíveis formações acadêmicas: mestre em Saúde Pública pela Fundação Oswaldo Cruz (Fiocruz) e especialista em Políticas Públicas pela Universidade Federal de Goiás (UFG) (Mattos, 2016).

Camargo Jr. (2013), ao falar sobre a obra de Conrad, utiliza o conceito de "tirania da saúde" elaborado pelo autoro, termo cunhado para designar outro aspecto presente no processo de medicalização da saúde, ou de exaltação da saúde, que se manifesta em academias, suplementos alimentares, vitaminas para homens e para mulheres, restrições alimentares em prol da saúde. Segundo o autor, todas essas manifestações são herdeiras de uma interpretação equivocada da chamada “epidemiologia dos fatores de risco" (Camargo Jr., 2013, p.845), a qual culpabiliza os indivíduos pelo seu estado de saúde ou doença, individualizando os problemas sociais em diagnósticos clínicos ou em modelos ideais de saúde. Guarido (2007) 
também alerta para os efeitos da medicalização que apresenta como produto a banalização da existência, a naturalização do sofrimento e a culpabilização dos indivíduos.

Sendo assim, a construção do que hoje é chamado de medicalização não pode ser discutida sem antes observar as transformações que a antecederam. É possível notar, a partir do que foi exposto, que abarca tanto a via da patologização quanto a via de uma suposta saúde ideal. Concomitante, há uma expansão, na atualidade, de novos diagnósticos, novas síndromes. Será a partir dessa constatação que alguns autores, entre eles Conrad (1992; 2007), irão pautar uma das suas investigações como aquela que busca identificar quais fatores estariam concorrendo para o surgimento de uma síndrome.

De acordo com Conrad (1992), a crítica da medicalização repousa sobre como o modelo médico descontextualiza problemas sociais e os coloca paralelamente sob o controle médico, o que provoca uma individualização daquilo que poderia ser de outra forma visto como um problema social, coletivo. Desse modo, toda e qualquer questão como, por exemplo, o desempenho no trabalho, na vida social, o crescimento e o envelhecimento, tornam-se problemas de ajustes 'fisiológicos', recaindo, assim, sobre o reducionismo biológico, no imperialismo e na normatividade dos diagnósticos que tomam o lugar de controle sobre a vida.

Conrad e Barker (2011) realizam um levantamento das raízes do construcionismo social e de suas descobertas e efeitos em relação ao campo da saúde. O construcionismo social pode ser definido, de acordo com os autores supracitados, como um conjunto de teorias que buscam enfatizar os aspectos culturais e históricos dos fenômenos, especialmente aqueles considerados naturais. Além disso, a pesquisa através dessa perspectiva aponta para o fator contributivo de indivíduos e grupos na produção de uma realidade ou, assim como é o caso deste artigo, na produção de uma ideia sobre o adoecimento. Conrad e Barker (2011, p.197) fazem uma afirmação paradigmática nesse sentido: "Não só a doença, mas também a experiência de uma doença é construída socialmente”.

Assim, à luz do que é proposto por Conrad (2007) e Conrad e Barker (2011), é possível compreender a doença ou síndrome como produtos de uma tensão entre as diferentes perspectivas médicas e científicas, as quais são também influenciadas pela dimensão social. Segundo os autores,

O conhecimento médico sobre as enfermidades não é necessariamente encontrado objetivamente na natureza, mais do que isso, ele é construído e desenvolvido por indivíduos e grupos reivindicadores e partes interessadas que frequentemente possuem uma forte agenda política, carregada de juízos de valor (Conrad \& Barker, 2011, p. 212).

A partir do que foi exposto, pode-se observar quão complexo é o conceito de medicalização. Ele é atravessado por momentos históricos distintos, todos com o seu grau de importância para o desenvolvimento não só do conceito, mas das pesquisas sobre o tema. Cabe agora relacionar as duas visões das quais partimos a respeito desse processo e suas implicações na clínica psicológica contemporânea.

\section{Reflexos da Medicalização para a Clínica Psicológica Contemporânea}

Desde as primeiras manifestações dos estudiosos em relação ao tema da medicalização, na década de 1950, atingindo seu ápice em 1980, percebeu-se um alargamento dos limites das categorias diagnósticas. Esse aumento foi influenciado pelas mudanças enfrentadas pelas grandes potências, dentre as quais o pós-guerra e o neoliberalismo, assim como o desenvolvimento tecnológico que serviu de propulsor das indústrias farmacêuticas e midiáticas.

A expansão dessas categorias é também exemplificada por Camargo Jr. (2013) quando relata sobre a descoberta do HIV e AIDS nos anos 1980. Não havendo conhecimento sobre as doenças naquele momento, foi preciso uma investigação. A partir dos relatos dos pacientes e do incentivo às pesquisas sobre o fenômeno, foi possível a instauração de uma nova categoria diagnóstica. Só assim a medicina desenvolveu seu arcabouço teórico e científico, conseguindo, desse modo, identificar os possíveis "pacientes", além de criar um coquetel de medicamentos que permitiam o prolongamento da vida desses indivíduos.

No exemplo supracitado, observa-se uma comunhão de fatores que se articulam em prol do desenvolvimento de um saber sobre a vida; no caso, a medicina. É possível perceber que há um papel delegado à sociedade em legitimar ou reconhecer determinados fenômenos relativos à saúde. Da mesma forma, a intervenção da indústria farmacêutica se torna cada vez mais presente nessa dinâmica de autorização de diagnósticos.

Vaz (2015) traça uma discussão a respeito da mudança de paradigma que permitiu a transição da figura do "anormal" para a figura de consumidor de medicamentos e de doenças na atualidade. Ele aponta que a mudança no conceito de doença permitiu que os critérios diagnósticos saíssem do campo estrito do comportamento desviante e se encontrassem, na contemporaneidade, expandidas a um modelo ideal de felicidade, de saúde e de comportamento. Vaz (2015, p.55) ainda demonstra que para pensar o aumento do número de doenças, principalmente as doenças mentais, é preciso estabelecer um 
nexo entre diversos fatores, entre eles: "as mudanças nas categorias diagnósticas, estratégias terapêuticas predominantes, funcionamento da economia, e nos valores culturais hegemônicos da sociedade".

Nesse mesmo sentido, no Seminário Das Paredes às Redes (Jorge \& Oliveira, 2013), Paulo Vaz trata sobre a expansão do número de diagnósticos a partir da sexta versão do CID. Ele aponta que houve uma comunhão de fatores, por exemplo, a tecnologia médica, as pesquisas da indústria farmacêutica e da mídia, que concorreram para instaurar uma nova doença e por consequência a necessidade de tratamento da mesma. Mas, acima de tudo, ele afirma que foi preciso criar um modo de identificação da própria população em relação à doença. Dessa forma, cada vez mais comportamentos, antes tidos como naturais, foram sendo enquadrados nas categorias diagnósticas.

Os efeitos desse novo olhar sobre a doença para a clínica são inúmeros. Guarido (2007) analisa as mudanças que ocorreram em relação ao sofrimento psíquico ao longo dos anos e os fatores que contribuíram para tal mudança. Entre os fatores citados pela autora, estão: a padronização de sintomas trazida pelo DSM, as pesquisas no campo da neurociência que circunscrevem o funcionamento psíquico em bases orgânicas, e o desenvolvimento dos psicofármacos. O reflexo da atuação desses fatores pode ser encontrado na naturalização do sofrimento psíquico, com a perda do significado atribuído aos sintomas e, em articulação com os autores previamente citados, o processo de medicalização da sociedade.

Há, portanto, um movimento na atualidade de culpabilização dos indivíduos pelo seu estado de saúde ou doença. O sentimento de mal-estar, por exemplo, leva o indivíduo a uma busca desenfreada por especialistas que possam, a partir do seu conhecimento, atribuir um nome, um código que identifique ou localize o mal-estar em uma doença. Além disso, que possa ser tratada e curada através das intervenções, tidas como cada vez mais avançadas, do saber médico, ou pela adoção de um novo estilo de vida divulgado pelos meios midiáticos.

Esse é o rótulo com o qual os indivíduos se deparam, e não o seguir é o mesmo que assumir a responsabilidade pela sua condição de doente. Em relação às intervenções que são propostas na atualidade, uma das mais comuns é o uso de psicofármacos. Guarido (2007) afirma que a construção de conhecimento acerca do sofrimento está associada à produção da indústria farmacêutica, a qual está alicerçada na crença do alívio ou extermínio dos sofrimentos existenciais. De todo modo, como afirma a autora

Não se trata de rejeitar todo e qualquer uso dos psicofármacos, pois são inegáveis alguns de seus efeitos positivos tanto na vida de alguns como na possibilidade de transformação do sistema de cuidados e tratamento da loucura no século XX, mas de evidenciar os efeitos de um discurso que banaliza a existência, naturaliza os sofrimentos e culpabiliza os indivíduos por seus problemas e pelo cuidado de si (racionalização própria da economia neoliberal). (Guarido, 2007, p.159)

Ainda sobre os efeitos da mudança no conceito de doença, Guarido (2007) aborda a questão das possibilidades de tratamento que são oferecidas aos indivíduos, mais especificamente a criança e sua família. Ela afirma que o fato de as terapias cognitivas serem as mais reconhecidas pelo saber médico implica num olhar médico-psicológico que pode restringir as possibilidades de interpretação do sofrimento, descontextualizando-o e não oferecendo outros olhares além daquele da normatização.

\section{Considerações Finais}

A discussão da temática da medicalização e suas implicações na clínica psicológica evidenciam a complexidade desse campo de estudo, revelando principalmente um modo de operar da sociedade ocidental contemporânea. Como foi abordado, a contemporaneidade foi tomada a partir de uma perspectiva historiográfica, podendo ser analisada através das rupturas ou continuidades filosóficas e culturais com o período que a antecede. Segundo Giddens (1991), seria possível observar que, na atualidade, há uma radicalização de características modernas, entre as quais estariam a perda dos referenciais, a ausência de um destino para localizar as "queixas" e o sofrimento, bem como a cultura da individualidade, que tem como consequência direta a valorização da competitividade, tão corrente no neoliberalismo. Esses aspectos parecem absolutamente articulados à lógica medicalizante, de modo que ela se mostra fortemente associada às demandas endereçadas à clínica na contemporaneidade.

Este artigo buscou articular conceitualmente duas visões sobre o fenômeno identificado como medicalização e os seus efeitos na clínica. A princípio, Illich (1975) alerta para um novo papel exercido pela medicina sobre o controle da sociedade, além das influências do saber médico sobre a cultura de um grupo. Para ele, entretanto, a sociedade ainda estaria numa posição de receptividade (passiva) do saber médico e da técnica, posição que foi colocada em perspectiva em momento posterior. Já para Conrad (1979; 1992; 2007), o processo de medicalização é sócio-cultural e advém de uma construção em uma determinada sociedade. Como foi evidenciado, ambos os autores vão destacar a ideia de que a sociedade e os indivíduos são corresponsáveis pela medicalização. Não se trataria de um imperialismo da medicina sobre os indivíduos, mas de uma identificação social com seus postulados. 
Outro ponto destacado foi o aspecto da busca patogênica da saúde, inaugurando a necessidade de atribuição de diagnósticos cada vez mais precisos e precoces, bem como da criação de terapias preventivas (Birman, 2006; Camargo Jr., 2013; Uhr, 2012). Esse movimento de busca por uma possível ameaça à saúde repercute nas práticas clínicas também no campo da Psicologia, fazendo com que os profissionais enquadrem seus clientes dentro de um possível diagnóstico. De acordo com Vaz (2015, p.52), "ser diagnosticado e tratado por um transtorno mental será, portanto, um evento que ocorrerá à maioria dos indivíduos".

A importância dessa discussão para a clínica psicológica está ligada à possibilidade de, a partir do reconhecimento dessa dinâmica, oferecer uma postura crítica, com uma atuação que permita a valorização da singularidade e uma clínica que atue com um modus operandi não medicalizante. Essa forma de atuação implica em reconhecer que o exercício da clínica está vinculado aos jogos de poder, ou seja, são espaços privilegiados de produção de subjetividade, como afirma Foucault (2015), onde existem forças que concorrem para a produção de certos modos de viver, saber e de poder. A aliança com forças que compactuam com o discurso tido como hegemônico é que incorre na problemática trazida pelo fenômeno da medicalização, qual seja: a cristalização das demandas em diagnósticos, a exaltação dos especialismos no lugar da clínica ampliada e o processo de individualização no lugar da valorização da singularidade. A esse respeito, Gondar (2009) afirma

Investir em mudanças no campo subjetivo é combater práticas de assujeitamento que fecham ou esgotam o campo de possíveis, propiciando a criação de outros possíveis ou mesmo do próprio possível, quando o campo parece esgotado (2009, p.127).

O que a autora traz nesse fragmento permite refletir a respeito da prática clínica e daquilo que se produz ao tomar determinado direcionamento. A produção de mundos onde a diferença, a singularidade e a criação sejam de fato acolhidas para além do imperativo diagnóstico. $\mathrm{O}$ fenômeno da medicalização se estabelece como paradoxo, pois, ao mesmo tempo em que emerge para dar lugar ao sofrimento, ao mal-estar, a diversas "doenças" da contemporaneidade, ele desvela também o modo de produção de subjetividade no qual se está imerso.

Nesse sentido, é possível pensar se a aderência das práticas de saúde ao discurso medicalizante não pode ser interpretada como uma denúncia da maneira como está funcionando a produção de subjetividade na atualidade. Trata-se, sobretudo, da associação de um discurso que parece hegemônico e que prima pela patologização da vida, pela normatização das diferenças e pela busca da individualização de questões que são atravessadas pela história, pela política, pela economia e pela cultura, não podendo, portanto, estarem dissociadas desses aspectos.

Assim, é possível afirmar que a psicologia, quando lança mão de uma prática que busca exclusivamente responder às demandas de uma cultura marcada pela exigência do consumo, pela valorização de um ideal humano inatingível de perfeição, entre outras características, acaba por recair num reducionismo da sua própria profissão. Desconsidera-se a valorização da singularidade e corrobora-se para a manutenção de uma cultura que parece só poder ser descrita através dos artifícios científicos e psicofarmacológicos. Caminhando na contramão dessa tendência, espera-se que a articulação de uma visão histórica à realidade vivida atualmente na clínica psicológica possa contemplar uma prática pautada na ética do cuidado e não na esperança da solução mágica frequentemente midiatizada.

\section{Referências}

Birman, J. (2006). A psicanálise e a crítica da modernidade. In J. Birman. Arquivos do mal-estar e da resistência (1 ${ }^{\mathrm{a}}$ ed., pp. 33-56). Rio de Janeiro: Civilização Brasileira.

Camargo Jr., K. R. (2013). Medicalização, farmacologização e imperialismo sanitário. Cadernos de Saúde Pública, 29(5), 844-846.

Conrad, P. (1979). Types of medical social control. Sociology of Health and Illness, 1(1), 1-12.

Conrad, P. (1992). Medicalization and Social Control.Annual Review of Sociology, 18, 209-232.

Conrad, P. (2007). The Medicalization of Society.On the Transformation of Human Conditions into Treatable Disorders. Baltimore: The Johns Hopkins University Press. Link

Conrad, P., \& Barker, K. K. (2011). A construção social da doença: Insights-chave e implicações para as políticas de saúde. Idéias, 3(2), 185-213. 
Foucault, M. (2015). Microfisica do Poder (3 ed.) Rio de Janeiro: Paz e Terra.

Giddens, A. (1991). As conseqüências da modernidade. (R. Fiker, Trad.) São Paulo: UNESP. Link

Gondar, J. (2009). A clínica como prática política. Lugar Comum, 19, 125-134.

Guarido, R. (2007). A medicalização do sofrimento psíquico: Considerações sobre o discurso psiquiátrico e seus efeitos na Educação. Educação e Pesquisa, 33(1), 151-161.

Henriques, R. P. (2012). A Medicalização da existência e o descentramento do sujeito na atualidade. Revista Mal-Estar e Subjetividade, 12(34), 793-816.

Henriques, R. P. (2015). Psicopatologia e medicalização: Políticas da cumplicidade. In D. M. Coelho, \& E. L. Cunha. Saber \& Violência (pp. 57-67). São Cristóvão: Editora UFS.

Hobsbawm, E. (1995). Era dos Extremos: O breve século XX (1914 - 1991). São Paulo: Companhia das Letras.

Illich, I. (1975). A expropriação da saúde: Nêmesis da medicina. (3ºd.). Rio de Janeiro: Nova Fronteira. Link

Jardim, A., \& Oliveira, O. F. (2009). Globalização, neoliberalismo e Estado-Nação: Reflexões analíticas. Perspectiva Sociológica, 2(3), 1-15. Link

Jorge, M. F., \& Oliveira, T. (Produtores). (2013). Seminário das paredes às redes [Youtube]. Link

Laurenti, R. (1991). Análise da informação em saúde: 1893-1993, cem anos da Classificação Internacional de Doenças. Novos aspectos da Saúde Pública. Revista de Saúde Pública, 25(6), 407-417.

Mattos, G. (2016). Homem oferece curso online para ‘cura gay' e entra na mira do MPF. O Dia online. Link

Nogueira, R. P. (2003). A segunda crítica social da Saúde de Ivan Illich. Interface - Comunicação, Saúde, Educação, 7(12), $185-190$.

Rocha, A. E. S. (2012). Trabalho, Corpo e Identidade: O Humano na Modernidade e na Contemporaneidade. Revista Diálogos:Revista de Estudos Culturais e da Contemporaneidade, 6(1), 158-173. Link

Uhr, D. (2012). A Medicalização e a redução biológica no discurso psiquiátrico. Polêmica Revista Eletrônica, 11(3), 396403. Link

Vaz, P. (2015). Do Normal ao consumidor: Conceito de doença e medicamento na contemporaneidade. Revista Ágora, 18(1), 51-68. DOI: 10.1590/S1516-14982015000100005

Viégas, L., S., Harayama, R. M., \& Souza, M. P. R. (2015). Apontamentos críticos sobre estigma e medicalização à luz da psicologia e da antropologia. Ciência \& Saúde Coletiva, 20(9), 2683-2692. DOI: 10.1590/1413-81232015209.08732015

Zorzanelli, R. T., Ortega, F., \& Bezerra Jr., B.(2014). Um panorama sobre as variações em torno do conceito de Medicalização entre 1950 - 2010. Ciência e Saúde Coletiva, 19(6), 1859-1868. 


\section{Anexos}

1. Revisão da Classificação Internacional de Doenças segundo o ano em que foi adotada, anos de uso e número de categorias. (Laurenti, 1991)

\begin{tabular}{|c|c|c|c|c|c|c|}
\hline Revisões & $\begin{array}{c}\text { Ano da } \\
\text { conferência que } \\
\text { a adotou }\end{array}$ & Anos de uso & Doenças & C. Externas & $\begin{array}{c}\text { Motivos } \\
\text { Assist. } \\
\text { Saúde } \\
\end{array}$ & Total \\
\hline Primeira & 1900 & 1900-1909 & 157 & 22 & & 179 \\
\hline Segunda & 1909 & $1910-1920$ & 157 & 32 & & 189 \\
\hline Terceira & 1920 & 1921-1929 & 166 & 39 & & 205 \\
\hline Quarta & 1929 & $1930-1938$ & 164 & 36 & & 200 \\
\hline Quinta & 1938 & $1939-1948$ & 164 & 36 & & 200 \\
\hline Sexta & 1948 & $1949-1957$ & 769 & 153 & 88 & 1.010 \\
\hline Sétima & 1955 & $1958-1967$ & 800 & 153 & 88 & 1.041 \\
\hline Oitava & 1965 & 1968-1978 & 858 & 182 & 48 & 1.088 \\
\hline Nona & 1975 & 1979-1992 & 909 & 192 & 77 & 1.178 \\
\hline Décima & 1989 & 1993-2002(?) & 1.575 & 373 & 82 & 2.032 \\
\hline
\end{tabular}




\section{Quadro de conceitos}

\begin{tabular}{lcc}
\hline \multicolumn{1}{c}{ Conceito } & Contexto & Autores \\
\hline Medicina como meio de controle social & 1951 & Talcott Parsons \\
\hline Alargamento do conceito de doença mental & 1950 & Barbara Wootton \\
\hline & 1960 & Thomas Szasz \\
Expansão do saber psiquiátrico sobre o cotidiano dos indivíduos & 1950 & Becker \\
\hline $\begin{array}{l}\text { Teoria do rótulo - considera o desvio como transgressão àquilo } \\
\text { que foi estabelecido como norma num grupo. }\end{array}$ & 1963 & \\
\hline
\end{tabular}

Amplia a discussão do campo da psiquiatria para a sociologia médica. Discute os processos de classificação do crime, loucura, pecado e pobreza como categorias de doença.

Critica o monopólio médico e os efeitos iatrogênicos do mesmo. Onipresença do transtorno

Eliot Freidson

Critica o imperialismo médico (supervisão médica de todos os aspectos ordinários da vida).

\section{Cultura medicalizada}

Iatrogênese (epidemia de doenças provocadas pela medicina).

Dependência da autoridade médica (iatrogênese social).

Irving Zola


Biomedicalização - campo biopolítico de atuação que inclui o nível molecular. Os serviços e tecnologias médicas são cada vez mais intricadas e com foco na otimização e aperfeiçoamento individual, elaboração do risco e da vigilância no nível individual, grupal e populacional.

Não utiliza a expressão medicalização, mas depreende-se o conceito a partir de sua obra.

Discute a ação do saber médico sobre o corpo ao longo dos séculos XVII, XVIII, XIX.

Intervenção sobre o espaço público

Foucault

1990

Biopoder - exercício sobre os corpos por meio da tecnologia disciplinar.

\section{Endereço para correspondência}

Lívia Machado Silva

Email: liviamachadosilva@gmail.com

Fernanda Canavêz

Email: fernandacanavez@gmail.com 